\title{
Robótica e Interdisciplinaridade: Aprendizagem Criativa Atraindo Meninas para a Tecnologia
}

\author{
Christiane Borges Santos ${ }^{1}$, Audir da Costa Oliveira Filho ${ }^{1}$ \\ ${ }^{1}$ Instituto Federal de Goiás - Câmpus Luziânia \\ Endereço da Instituição \\ \{christiane.santos, audir.filho\}@ifg.edu.br
}

\begin{abstract}
This paper describes the project of teaching robotics and creative learning in an interdisciplinary methodology. Students apply the knowledge acquired in high school classes in the robotics laboratory that uses the STEAM methodology (Science, Technology, Engineering, Arts and Mathematics), as access points to guide research, dialogue and scientific thinking. The main objective of the project is to show that girls can work in different areas of knowledge, including STEM areas (Science, Technology, Engineering and Mathematics).
\end{abstract}

Resumo. Este artigo descreve o projeto de ensino de robótica e aprendizagem criativa em uma metodologia interdisciplinar. As estudantes aplicam o conhecimento adquirido nas aulas do ensino médio no laboratório de robótica utilizando a metodologia STEAM (Science, Technology, Engineering, the Arts and Mathematics), como pontos de acesso para orientar a investigação, $o$ diálogo e o pensamento crítico. O principal objetivo do projeto é mostrar que as meninas podem atuar em diferentes áreas do conhecimento, incluindo as áreas STEM (Science, Technology, Engineering and Mathematics).

\section{Introdução}

A resistência - quando a menina diz que quer fazer computação ou alguma área tecnológica - começa em casa, com os pais e familiares. Desde criança, normalmente se tem a cultura de presentear meninas e meninos com brinquedos diferentes. Enquanto o menino tende a ganhar brinquedos que provavelmente contribuirão para o seu desenvolvimento intelectual e raciocínio lógico, as meninas recebem bonecas. Os brinquedos ajudam no desenvolvimento de habilidades e da imaginação. Constroem autonomia, exploram, ensinam e reproduzem comportamentos. São partes muito importantes na vida das crianças, e isso pode trazer boa influência, despertando o talento para algumas profissões. Nesta fase, também inicia-se um tabu: o das profissões masculinas ou femininas. Em 1992, a Mattel Toys lançou uma boneca Barbie falante dizendo "A aula de matemática é tão difícil". A boneca tornou-se controversa, especialmente entre pais e professores, que achavam que isso reforçava o estereótipo de que as meninas não são boas em matemática (BBC Brasil, 2020).

A história mostra uma utopia de que ciências exatas são áreas restritas a homens ciências humanas restritas a mulheres, descartando a contribuição intelectual das mulheres para o desenvolvimento da área de Tecnologia da Informação (TI). Por exemplo: Ada Byron (Lady Lovelace), conhecida como a primeira programadora da história, Grace Murray Hopper, que contribuiu no desenvolvimento da linguagem de programação COBOL, Marina C. Chen, que projetou e implementou os compiladores Fortran, Adele Goldberg, que trabalhou na criação da primeira interface baseada em ícones, Hedy Lamarr, atriz e responsável pela técnica de espalhamento espectral que 
serviu de base para algumas tecnologias de comunicação sem fio e Radia Perlman considerada "mãe da Internet" por sua invenção do protocolo Spanning Tree (Downs Hacker, 2020) (SANTOS, 2016). Devido a essas grandes mulheres, foi possível que o desenvolvimento tecnológico atingisse o grau atual, permitindo por exemplo a conectividade e o uso de tecnologias para que as pessoas pudessem trabalhar home office em tempos de pandemia.

Segundo o Instituto Nacional de Estudos Educacionais Anísio Teixeira (INEP), no Brasil o número de mulheres que cursam o ensino superior e o terminam excede o número de homens. Em 2017, as ingressantes do sexo feminino representavam 55,2\% do total geral de alunos matriculados. Analisando os 20 maiores cursos de graduação em número de matrículas e os respectivos percentuais de participação, pode-se identificar a predominância feminina em 14 deles, incluindo os três primeiros: Direito $(55,3 \%)$, Pedagogia $(92,5 \%)$ e Administração (54,9\%). Enquanto isso, nos três cursos de Engenharia desta lista existe a predominância masculina: Engenharia Civil (69,5\%), Engenharia de Produção $(65,0 \%)$ e Engenharia Mecânica (89,7\%). Por outro lado, há um equilíbrio nas áreas de saúde e agrária (INEP, 2020).

Estudos mostram que, ao vincular a teoria à prática, o aprendizado dos alunos é ampliado. Em cursos de computação, o abandono ocorre frequentemente porque os alunos encontram dificuldades em algum conceito teórico abstrato da computação já com as primeiras disciplinas. É necessário incentivar as estudantes do sexo feminino a ingressarem nas carreiras de ciências exatas, engenharias e computação desde cedo, para combater a evasão que ocorre principalmente nos primeiros anos destes cursos e despertando o interesse vocacional para a pesquisa cientifica e tecnológica (SANTOS, 2017) (BENETTI, 2012).

A robótica foi escolhida como metodologia de ensino por ser uma área de tecnologia que inclui mecânica, metareciclagem, eletrônica e computação, que atualmente se refere a sistemas compostos por máquinas e peças mecânicas automáticas, controladas por circuitos elétricos. A metareciclagem é uma forma consciente de reciclar o lixo eletrônico que consiste na desconstrução do lixo tecnológico para a reconstrução da tecnologia. Os princípios da Metareciclagem têm por base a desconstrução do hardware, o uso de softwares livres, o uso de licenças abertas e a ação em rede, buscando a formação de uma idéia sobre a reapropriação de tecnologia objetivando a transformação social. Além disso, a aplicação prática da robótica inclui áreas como a de domótica (automação residencial), mecatrônica (automação industrial), IoT (Internet das Coisas) e o mercado de trabalho é promissor. O crescimento no mercado de robôs pessoais, incluindo aqueles usados para fins educacionais e de entretenimento, tem sido enorme e essa tendência pode continuar nas próximas décadas (BENITTI, 2012) (PEREIRA, 2010) (PINTO, 2011) (SANTOS, 2016) .

Graças a "cultura" de diferenciação entre brinquedos de meninos e meninas, muitas vezes as jovens não se interessam em abordagens tradicionais de robótica, mas tornam-se motivadas quando as atividades de robótica são introduzidos como uma maneira de contar uma história, participar de uma competição ou em conexão com outras disciplinas e áreas de interesse. A robótica acaba se tornando uma forma lúdica para aprimorar o aprendizado de diversos conceitos, e as meninas se sentem motivadas a desenvolverem projetos de uma forma divertida e inter-disciplinar. Além disso, a robótica aliada ao ensino e a lógica de programação, ajuda no desenvolvimento do 
raciocínio lógico e dedutivo das alunas. E mesmo que as mesmas optem por outros ramos profissionais, terão desenvolvido competências de resolução de problemas que serão úteis em suas respectivas áreas do conhecimento.

O artigo está definido da seguinte forma: a introdução discutiu o contexto e os conceitos históricos sobre a participação feminina na tecnologia, e a motivação do uso da robótica como metodologia de aprendizagem. A seção 2 apresentará os conceitos de robótica e sua aplicação interdisciplinar no laboratório. A seção 3 trará resultados parciais com o modelo adotado e a seção 4 abordará as conclusões.

\section{Robótica e Aprendizado Criativo}

\subsection{Interdisciplinaridade}

A robótica como forma de auxílio na educação é um dos grandes debates no Brasil. A Campus Party e o Latinoware (Congresso Latino-Americano de Software Livre e Tecnologias Abertas) por exemplo, são grandes eventos internacionais que acontecem no Brasil e possuem amplo debate na área de Educação Criativa. Vários países já exploram a Robótica em instituições de ensino em diversos níveis de escolaridade. Sob o ponto de vista tecnológico para educação, a robótica é uma tecnologia emergente que tem se tornado elemento praticamente obrigatório nas escolas modernas devido à sua possibilidade de atuação em diversas dimensões.

No entanto, muitas pesquisas enfocam o uso da robótica no ensino fundamental ou como mecanismo de apoio no ensino de disciplinas de graduação. Aprender robótica no ensino médio de maneira interdisciplinar e prática para atrair jovens para a tecnologia não é tão discutido. Poucos estudos têm evidências empíricas para provar o impacto da robótica na aprendizagem e não há evidências de pesquisas para apoiar seu impacto direto no desempenho acadêmico dos estudantes. Os professores começaram a ter idéias e desenvolver atividades para incorporar a robótica ao ensino em diferentes disciplinas, incluindo matemática, ciências e engenharia. Com isso, as atividades de robótica podem ser apenas uma "tendência" (BENITTI, 2012) (PEREIRA, 2010) (PINTO, 2011).

Seymour Papert acredita que "A maior vantagem competitiva é a habilidade de aprender". Papert foi um dos primeiros a reconhecer a dimensão transformadora assumida pela tecnologia na sociedade, capaz de alterar o modo como as pessoas pensam, trabalham, divertem-se e aprendem. Segundo Papert "Podemos aprender mais e mais rapidamente se tomarmos o controle consciente do processo de aprendizagem, expressando e analisando nosso comportamento". Nessa visão, o aprendizado ocorre por meio do fazer, do "colocar a mão na massa", e quando o aluno constrói algo do seu interesse ou para o qual está motivado (PAPERT, 1986).

A maioria dos trabalhos que enfatizam o uso da robótica como ferramenta de ensino são teóricos, com base em relatos de professores que alcançaram resultados positivos. Muitos desses trabalhos estão focados na robótica em assuntos intimamente relacionados com o planejamento e construção de robôs utilizando kits proprietários, como o kit Lego Mindstorms. O Lego Mindstorms é muito intuitivo e parece "brinquedo". É possível programar usando um computador ou diretamente na interface dele, que é considerada como o cérebro da máquina. Embora sejam interessantes para o ensino de robótica, os kits da Lego não são compatíveis com outras soluções de baixo- 
custo, e necessitam de peças e sensores específicos, além de cobrar taxas de licenciamento para utilização completa do software no computador, o que torna $o$ projeto financeiramente inviável em muitos casos.

Existem diversas ferramentas open source que podem introduzir essas meninas no mundo da robótica e da programação, como por exemplo o Scratch, uma linguagem de programação baseada em interface gráfica e que tem integração com hardwares (S4A, 2020) para construção de robôs, como a plataforma Arduino, e o Alice, um ambiente de programação tridimensional de fácil utilização, no qual podem ser criadas animações e interações entre personagens e objetos, e que lembra muitos jogos de videogames (ARDUINO, 2020) (ALICE, 2020).

O projeto tenta buscar além do desenvolvimento de significado, o interesse, envolvimento e a criatividade das educandas, motivando o conhecimento através da "aprendizagem criativa". O conceito de aprendizagem criativa (Creative Learning) nasce a partir das ideias de Friedrich Froebel (criador do jardim da infância) e das descobertas de John Dewey e Seymour Papert em relação às formas que potencializam a aprendizagem.

A aprendizagem criativa consiste em uma filosofia de educação fundamentada em quatro pilares(4Ps): project, passion, peer learning e play) É uma prática pedagógica baseada em projetos (projects), em que os alunos são movidos pelo significado (passion), produzem de forma colaborativa (peer learning) e são valorizados por competências como criatividade, curiosidade e resiliência (play). Esse conceito coloca os alunos no centro do processo educativo, proporcionando condições para que planejem, criem, testem, em situações reais do cotidiano, atuando de forma ativa perante os problemas sociais e as temáticas que as envolvem (MARTINEZ, 2019).

Segundo Mitchel Resnick, "Quando você aprende através da escrita de códigos, e escreve códigos para aprender, você está aprendendo em um contexto significativo, $e$ esta é a melhor forma de aprender as coisas" (RESNICK, 2020). Desta forma, no laboratório, as alunas são constantemente motivadas e preparadas para participarem em competições de robótica como a Olimpíada Brasileira de Robótica (OBR), oficinas e palestras em eventos de tecnologia.

\subsection{Laboratório}

O projeto Metabotix se concentra em meninas que estão cursando o ensino médio, incentivando essas estudantes a concluírem o curso técnico e seguirem nas carreiras de ciências exatas, engenharia e computação. Parte do objetivo do projeto também é evitar o abandono escolar, que ocorre principalmente nos primeiros anos desses cursos de graduação, e aumentar o interesse vocacional à pesquisa científica e tecnológica.

O projeto existe desde 2014 e tem como foco mostrar às meninas que ingressam no ensino médio que áreas STEM podem ser interessantes e que o mercado de trabalho está crescendo. Mas também alerta sobre as possíveis dificuldades que podem ser encontradas na construção de uma carreira na área.

No laboratório são desenvolvidos projetos de iniciação científica, estágio e trabalhos de conclusão de curso relacionados a robótica e hardware livre, além de 
preparar alunos de nível médio para competições regionais e nacionais de robótica, como a OBR (Olimpíada Brasileira de Robótica). Já foram desenvolvidos no laboratório 05 trabalhos de iniciação científica, 01 trabalho de conclusão de curso, 01 atividade complementar e 03 projetos de ensino, em parceria com professores de Química, Física e Informática e alunos egressos do IFG (OBR, 2020). Atém disso, o Laboratório é comunidade parceira da Campus Party Brasil.

Atualmente, as estudantes envolvidas no projeto são desafiadas a construir e programar pequenos robôs, oferecendo a oportunidade de experimentos com vivências semelhantes às encontradas na vida real, melhorando o desempenho escolar e gerando benefícios como motivação, criatividade, desenvolvimento de pensamento lógico e interação em grupo.

O projeto possui como etapas de ambientação e experimentação:

- Sensibilização: apresentação do tema e estabelecimento de relacionamento colaborativo entre professores e alunas;

- Programação Lógica: programação de blocos e Arduino IDE;

- Robótica: integração de propostas educacionais;

- Treinamento básico: conceitos elétricos e eletrônicos;

- Planejamento do projeto: dispositivos, software, idiomas e interface utilizadas;

- Experimentação: testes iniciais dos protótipos;

- Montagem: interface dos dispositivos, programação.

O desenho todo do projeto é baseado no uso de software e hardware abertos / gratuitos. São utilizados no laboratório sistemas operacionais GNU / Linux e a plataforma de hardware Arduino UNO. Existem muitos kits de robótica no mercado, mas o uso de metareciclagem e de plataformas de hardware livres permitem maior flexibilidade para o projeto e um maior custo-benefício.

Para introduzir as estudantes no mundo da programação, as versões Scratch, S4A e a própria IDE Arduino foram adotadas. Elas também aprendem no laboratório ou revisam conceitos de eletricidade e eletrônica, identificação de componentes eletrônicos e montagem de circuitos elétricos na protoboard. E utilizam conceitos de montagem e manutenção de computadores para coletar e catalogar peças que podem ser reutilizadas para a construção de projetos a partir de equipamentos antes do descarte.

Todo início do ano (desde 2016) o laboratório realiza um projeto de ensino para revisar matérias que estão no conteúdo das provas teóricas da OBR, aberto para todos os alunos. Os alunos que participam do projeto sempre obtêm um desempenho melhor do que aqueles que não participam. Vale ressaltar que medalhistas da OBR concorrem a vagas nas principais universidades públicas do país, como por exemplo UNIFEI, UNESP, USP e UNICAMP.

No início do projeto existia uma pouca adesão para participação nas provas teóricas da OBR, mas isso foi aumentando ao longo dos anos como mostra a Figura 1. O conteúdo das provas abrange os três anos do ensino médio, mas todos são incentivados a participarem das provas desde o primeiro ano, para acompanharem a evolução do aprendizado. 


\section{Participação dos Alunos do Curso Técnico em Informática na OBR}

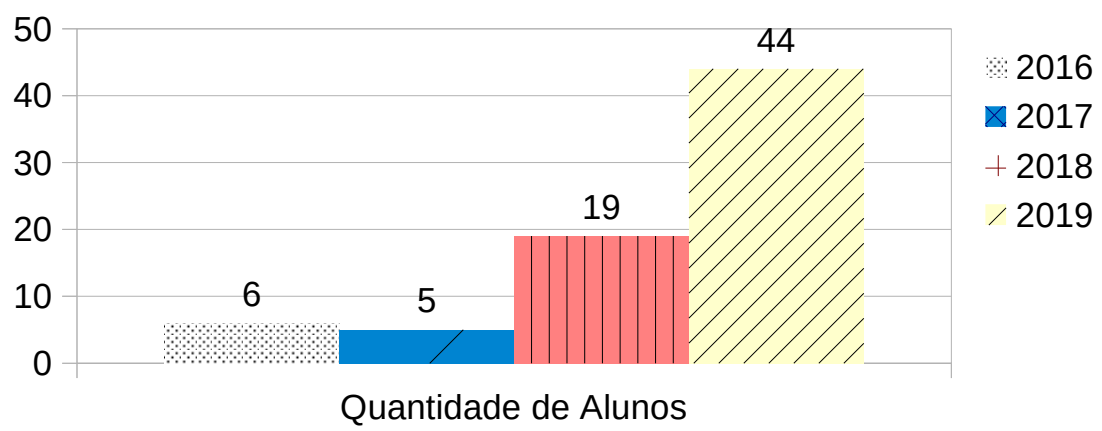

Figura 1 - Participação dos Alunos do Curso Técnico em Informática do IFG Campus Luziânia na OBR - Modalidade Teórica

\section{Resultados}

Interessantes experiências têm demonstrado que a robótica pode atuar como inclusiva, não apenas digitalmente ou tecnologicamente, mas socialmente, levando estudantes a se integrarem de maneira efetiva à sua comunidade escolar e à sociedade.

O projeto está em fase de andamento, mas já pode ser percebida uma maior motivação e interesse dos alunos em seguir áreas de exatas, tecnologia e engenharia. As alunas estão obtendo desempenho satisfatório, algumas vezes melhor do que o dos alunos, pelo menos para se qualificar para as próximas etapas.

No desenvolvimento do protótipo, as alunas geralmente escolhem um problema e tentam resolvê-lo usando robótica, lógica de programação e conceitos de metareciclagem. Para a montagem desses protótipos, a possibilidade de metareciclagem, eletrônica em geral e brinquedos fora de uso pode ser usada total ou parcialmente, não se limitando apenas aos materiais de informática.

A Figura 2 mostra alguns protótipos desenvolvidos no projeto, um robô seguidor de linha para usar em competições de robótica e um robô Lego. O objetivo do robô seguidor de linha é seguir um caminho predeterminado, e o vencedor é o mais rápido. Geralmente, o caminho a seguir é uma linha com contraste de cores com o solo, em preto e branco, em geral. O robô é totalmente autônomo, não sendo permitida nenhuma influência dos alunos na operação do robô, que deve detectar a rota através dos sensores. Parte do projeto envolve o desafio da programação lógica para interpretar os sinais recebidos pelos sensores e fazer com que o robô atenda corretamente à rota, identificando linhas, curvas e possíveis desafios do percurso. 


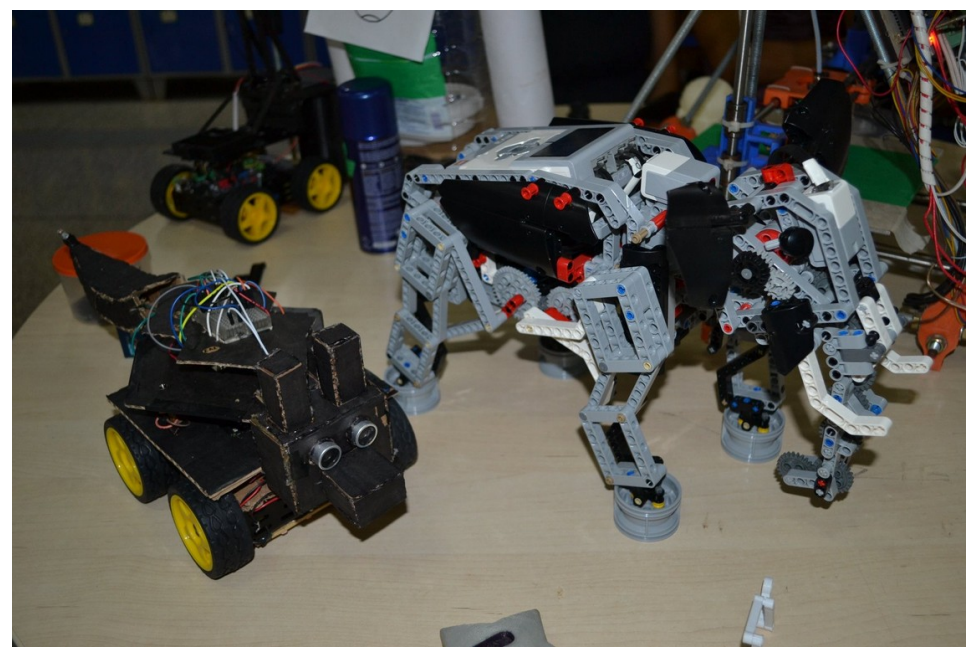

Figura 2. Criando um robô seguidor de linha

Em 2016, no primeiro ano com projeto de ensino, uma aluna recebeu medalha de Honra ao Mérito por seu desempenho expressivo na primeira prova da Modalidade Teórica da OBR. Em 2019, um aluno e uma aluna foram para a segunda fase da OBR e receberam medalhas de bronze e prata, respectivamente. Na prova prática, um grupo misto (02 alunos e 02 alunas) recebeu a medalha "Dedicação", por seu desempenho na competição, ao criar um robô seguidor de linha utilizando Arduino, sensores, metareciclagem e peças impressas em uma impressora 3D.

Também em 2019, 03 alunas do laboratório conquistaram o Segundo Lugar lugar em um desafio Oficina de Chão (promovido pela Coca-Cola) na Campus Party Brasilia 2019. Na Oficina de Chão, de Alexandre Ferreira, os participantes usaram latas da Coca-Cola para aprender Robótica e construir um pequeno Robô de Mobilidade. Todos as alunas que participaram do projeto em 2019 foram aprovadas em cursos STEM em universidades públicas, e as meninas foram capazes de entrar em mais de uma universidade cursos como Engenharia de Redes de Comunicações, Sistemas da Informação, Engenharia Mecatrônica, Engenharia de Controle e Automação, Ciência da Computação e Engenharia de Software foram os escolhidos. Merece destaque a aluna medalhista da OBR, que conseguiu aprovação em 06 universidades públicas, 02 destas através da vaga olímpica.

O laboratório de robótica foi apresentado no jornal local da TV Anhanguera (Afiliada Globo), o que também aumentou a demanda por cursos relacionados à computação.

\section{Conclusão}

Muitos estudos focam crenças, valores e atitudes socialmente estabelecidos, formando estereótipos sobre as diferentes habilidades entre homens e mulheres. Quebrar esse paradigma de que a TI não é para as mulheres é essencial para uma nova geração de mulheres se sentir motivada a escolher essas áreas.

Através deste projeto que envolve robótica, aprendizagem criativa e interdisciplinaridade, as alunos aprendem, com o desafio de dominar os recursos de robótica, a construir seus próprios projetos, mesclando diferentes conteúdos, com práticas reais e concretas. Essas alunas desenvolvem uma abordagem mais ecológica, 
percebendo que elementos / componentes considerados descartáveis podem ser uma fonte de recursos para desenvolvimento de novos protótipos. Todos participantes do projeto compartilham trabalho, informações e conhecimentos, contribuindo para o capital intelectual de todo o grupo.

O projeto, sua metodologia e seus objetivos, estão sendo disseminados de acordo com a filosofia de projetos de software livre e hardware livre, oferecendo apropriação e desenvolvimento gratuitos a todos os interessados, traçando um perfil cooperativo e colaborativo.

O projeto é relativamente novo, mas já motiva a admissão de mulheres em cursos de educação superior. Agora, o objetivo é reduzir o abandono da educação universitária e incentivar as meninas do ensino médio que continuam no IFG para a educação universitária. Como meta para o trabalho futuro, espera-se motivar mais meninas jovens nas áreas STEM o mais rápido possível.

\section{Referências}

Alice Programming. Disponível em: <http://www.alice.org>. Acesso em maio de 2020.

Arduino. Disponível em: <http://www arduino.cc>. Acesso em maio de 2020.

BBC Brasil. Boneca Barbie celebra 50 anos como ícone cultural. Disponível em: $<$ https://www.bbc.com/portuguese/cultura/2009/03/090309_barbieshangaigd.shtml>. Acesso em maio de 2020.

BENITTI, Fabiane Barreto Vavassori. Exploring the educational potential of robotics in schools: A systematic review. Computers \& Education, 58, 978-988. 2012

Downs Hacker - Mulheres que revolucionaram a ciência e a tecnologia. Disponível em: $<$ https://www.downshacker.com.br/2020/03/mulheres-que-revolucionaram-a-cienciae-a-tecnologia/>. Acessado em junho de 2020

Entrevista para a TV Anhanguera - Robôs no IFG. Disponível em: $<$ https://www.facebook.com/watch/?v=2938085866212010>

INEP. Instituto Nacional de Estudos e Pesquisas Educacionais Anisio Teixeira. Resumo técnico do Censo da Educação Superior 2017 [recurso eletrônico]. - Brasília : Instituto Nacional de Estudos e Pesquisas Educacionais Anísio Teixeira, 2019. ISBN 978-65-81041-02-1 Disponível em: <http://portal.inep.gov.br/web/guest/resumostecnicos1>. Acesso em maio de 2020.

MARTINEZ, Sylvia Libow; STAGER, Gary S. Invent to Learn: Making, Tinkering, and Engineering in the Classroom. Constructing Modern Knowledge Press. 2019.

OBR - Olimpíada Brasileira de Robótica. Disponível em: < $\underline{\text { http://www.obr.org.br>. }}$ Acesso em maio de 2020.

PAPERT, Seymour. Constructionism: A New Opportunity for Elementary Science Education (1986).

PEREIRA, Gabriela Quirino. O Uso da Robótica Educacional no Ensino Fundamental: relatos de um experimento. Projeto Final de Curso de Bacharelado em Ciência da Computacao. Universidade Federal de Goiás, Campus Catalão. 2010

PINTO, Marcos de Castro. Aplicação de arquitetura pedagógica em curso de robótica 
educacional com hardware livre. Dissertação. Universidade Federal do Rio de Janeiro. Instituto de Matemática, Núcleo de Computação Eletrônica. 2011

Projeto Metarede. Portal. Disponível em: <http://metarede.com.br/o-que-emetareciclagem.php>. Acesso em junho de 2020.

RESNICK, Mitchel. Portal. Disponível em: <https://web.media.mit.edu/ mres $>$ Acessado em junho de 2020.

SANTOS, Verônica Gomes dos; GALEMBECK, Eduardo. Aprendizagem Criativa e Significativa como Estratégias para Trabalhar Ciências com as Crianças: Investigar, Criar, Programar. XI Encontro Nacional de Pesquisa em Educação em Ciências - XI ENPEC Universidade Federal de Santa Catarina, Florianópolis, SC - 3 a 6 de julho de 2017.

SANTOS, Christiane Borges; FERREIRA, Deller James; SOUZA, Maria Carolina Borim do Nascimento Rodrigues de; MARTINS, Andressa Rodrigues. Robotics and programming: Attracting girls to technology. In: 2016 International Conference on Advances in Computing, Communications and Informatics (ICACCI), Jaipur. International Conference on Advances in Computing, Communications and Informatics (ICACCI). p. 2052. 2016

SANTOS, Christiane Borges; LOJA, L. F. B.; FILHO , A. C. O.; MUNDIM , A. L. F. Robótica e Lógica de Programação como forma de atrair meninas ara a tecnológica. In: III Escola Regional de Informática de Goiás, 2015, Goiânia. III Escola Regional de Informática de Goiás, 2015. v. III.

S4A - Scratch for Arduino. Disponível em: <http://s4a.cat>. Acesso em maio de 2020.

Scratch - Imagine, Program, Share. Disponível em: <https://scratch.mit.edu/>. Acesso em maio de 2020. 